\title{
Instructional Improvement Through Individual Consultation
}

Deborah E. Simpson, Kathleen A. Dalgaard, and Clyde A. Parker

Recently increased concern regarding the quality of higher education has led to a variety of efforts to improve instruction (Nelson and Siegel, 1980; Gaff, 1975). Sharing this concern, various departments at the University of Minnesota have participated in an approach to instructional improvement based on ongoing consultation between individual instructors and an educational psychologist. Individual consultation has been used successfully as a means of improving instruction in a variety of educational settings (hospital rounds, preceptor case reviews, classroom labs, discussion, and lectures) with varying numbers of enrolled students (1-150). This paper summarizes the theoretical bases of individual consultation, describes this approach to instructional improvement, and provides an example to illustrate to approach used.

\section{Theoretical Bases}

\section{Theory 1: Instructional Interaction}

David Hunt $(1974,1978)$ argues that the outcomes of the teaching-learning process are a function of the learning environment created. This environment is continually modified by the interactions which occur between students, subject matter, instructional techniques 
(Jenkins, 1977) and the teacher. Understanding the learning environment requires understanding the interactions between a particular instructor, his material, his method of presentation, his instructional objectives, and his students.

\section{Theory 2: Student Differences}

The way in which a particular instructor thinks about his students affects how he will teach. Observing how one teaches a graduate course in clinical pharmacokinetics versus an undergraduate course in microbiology should reveal this distinction. However it frequently does not because instructors typically have very limited ways in which to think about students and teaching. For example, one faculty member asserted, "there are three kinds of students: those who will learn in spite of what I do, those who will learn because of what I do, and those who will fail to learn no matter what I do." Such limited constructs place constraints on the instructor's ability to increase the number of students who will learn "because of what (he) does."

Alternative ways of understanding students can lead to more effective instruction and learning. William Perry (1970) provides a useful framework for thinking about differences in students. Instructors want students to be able to analyze, synthesize, and evaluate information. Or as the most frequently summarized, "I want my students to think ..." Recent research (cf. Lawson, 1978), based on Perry's scheme of intellectual development indicates that the majority of college seniors are not able to think in the ways desired by faculty. This approach to describing differences in how students think about information can be used by the professor to design a learning environment which encourages the development of more appropriate thinking skills.

\section{Theory 3: Change}

So far, it has been assumed that the way the instructor talks about differences among his students will have a direct relationship to what he actually does in the classroom. However, Argyris and Schon (1977) found that people do not always do what they think they are doing, and more importantly, that few instructors are aware of any differences 
between what they think they are doing and what they are doing. For example, a professor needs to become aware of such incongruities as saying he wants students "to think in class" and simply lecturing from the book and testing for recall of facts.

\section{The Approach}

These three theories and their supporting research have led to an instructional improvement approach which involves individualized consultation with instructors to: (1) discuss the congruence of what they say with what they do; (2) provide alternative ways to think about students which can lead to instructional improvement; (3) discuss instructional techniques which may be appropriate in their setting based on the instructor's own style, his objectives, his content and the students in his course; and (4) create an environment in which the instructor is able to "think" about his instruction, practice new alternatives, and evaluate his own performance.

Instruction is viewed as an interactive process between teacher, students, outcome, teaching approach, and content. The goal of instructional consultation is to help faculty attain a more accurate conceptualization of factors affecting instruction. There are four major steps in the consultation process: (1) developing an understanding of the factors which the instructor views as critical to successful teaching; (2) comparing what the instructor says he wants to do with what he does, by means of observation, student interviews, and consultation; (3) exploring and using alternative teaching strategies based on the instructor's new conceptualization; (4) evaluating the "success" of new concepts and strategies in helping to create an instructional environment consistent with desired educational outcomes.

During all four steps the equality of status of the faculty member and consultant is maintained. By equality of status we mean that the content expertise of the instructor is united with the instructional expertise of the educational consultant for the agreed purpose of instructional improvement. The case of Professor Latham and his large lecture class in the College of Pharmacy illustrates the process of instructional consultation. 


\section{An Example}

\section{Step 1: Identify the Instructor's Major Concerns}

During conversation with Latham the consultant learned that Latham equated successful instruction with the ability of students to perform successfully in his course. According to Latham, the degree of success was primarily due to the student's possession and utilization of an "innate ability." Thus he explained differences in student performances in the following way: Students in the lower one-third of the class did not have "it" so they could not use "it." Students in the upper one-third had "it" and used "it." Students in the middle one-third had "it" but did not always use "it." Therefore his responsibility as an instructor was to motivate those who had "it" to use "it."

To rephrase Latham's conceptualization of successful teaching, if a student performs well it is because she has the ability to think and uses that ability either by her own inclination or as a result of the instructor providing the right motivation.

\section{Step 2: Challenge Instructor's Concepts of Teaching}

The idea of students possessing an "innate ability" to think is undeniably true at some level. However, the College of Pharmacy at the University of Minnesota has a selective admission program; there is a very low probability that students do not have the innate ability to succeed.

An alternative factor seems more plausible and more powerful in terms of improving student performance: differences in the students' learned ability to analyze, synthesize, and evaluate information.

Following a discussion of this hypothesis with Latham, the consultant gathered data through classroom observation and student interviews to test this alternative way of construing performance differences. Two major pieces of information were used to challenge Latham's conceptualization of instruction. First, his examinations required students to analyze various features of a microbiological problem, to explain why certain results could occur based on their knowledge of biological principles, and to evaluate particular actions. Successful performance on these examinations requires both knowl- 
edge of content and knowledge of how to use that content to evaluate pharmaceutical procedure.

The second challenge of Latham's conceptualization came from student interviews and directly addressed the question of motivation. The consultant interviewed fifteen randomly selected students who performed in the middle one-third of the class; Lata judged those students had "it" but did not use "it", thus they were defined as unmotivated. One "unmotivated" student attended every lecture, took notes during the lectures while concurrently taping lectures, each night reviewed the tape to fill in anything which she may have missed in her notes, read the text, then reread the took notes on the text and finally reviewed all notes several times before each exam.

All of the interviewed students indicated they had trouble with the problem section of the test. Comments such as these were typical: "don't know how to study for essays...Guess you just have to know everything," "after he went over answer in class it made sense...I knew it...but didn't know that it was what he wanted."

\section{Step 3: Formulate Alternative Teaching Approaches}

Toward the end of the course Latham began to reconceptualize his teaching. One opportunity to "train" students "how" to think occurred during the first half of a sixty-minute review session for the final examination. The consultant and Latham analyzed the mistakes students had made in responding to the problem questions (e.g., acting on only one of the several interacting features of the problem) and the steps used by Latham in solving the problem. The consultant assisted Latham in his understanding of the differences between successful and unsuccessful methods of approaching and solving problems. Using this understanding, they developed a teachable strategy which students could use in solving problems. The strategy was presented during the review session.

\section{Step 4: Evaluate New Approach}

Convergent data were used to evaluate Latham's reconceptualization of instruction. Three sources of data were available to assess the impact of the review session: (1) a statistical comparison of exam 
scores for those who attended the review session versus those who did not; (2) interviews of students who attended; (3) Latham's assessment of any changes in the way in which students solved problems. While each of these sources can be challenged, the findings from all three sources were consistent and supportive.

Comparison of examination scores. Fifty-four of 107 students voluntarily attended the review session. On the final examination separate totals for the problem and multiple choice sections were obtained. A comparison of treatment and control scores on the multiple choice section indicated no significant differences between the two groups.

Midquarter exam scores had been obtained five weeks before the final review session. Students who attended the final exam review session had scored an average of two points lower than those who did not attend. Therefore, an analysis of covariance was used to compare the performance of the two groups on the problem section of the final. Scores on the midterm were used to statistically control for differences in initial performance of the two groups. The analysis indicated that on the problem section of the final, the section which was the focus of the "treatment" effort, those who attended the review session scored significantly higher than those who did not (F1,101=9.64, p, 0.002).

Latham's comparisons of student performance on midterms and final. Latham grades all final exams with no knowledge of whether the papers belonged to those who had or had not attended the review session. Following the midterm, Latham's reactions to the students' responses were as follows: students did not answer the question asked; students added information to original; and students' responses were incoherent, disorganized, and somewhat random.

Latham's reactions to the final exam were as follows: "There seemed to be less groping...the answer the student settled on, whether right or wrong, was expressed concisely"; "There was evidence that the answers were compared back to the question as if the student was attempting to justify his answer with the information given."

Student interviews. Students were interviewed if they attended the review session and improved their performance from the midterm to the final exam by at least twenty points. Scheduling constraints limited the number of students to be interviewed to six. Two general types of 
responses were received from these students when asked how they explained their improved performance.

The first type of response was that the review session was a waste of time. The reason that these students attended was that "you never know if the teacher is only going to answer specific questions that you ask or if he is going to start talking about points to know for the exam." Most of the students interviewed indicated that the essay review section helped their performance on the final exam. One typical student said, "I can remember getting the final and turning to the problems right away and reading them and remembering about the problem that we did during the review session."

When asked to explain how they had approached the exam problem these students described the key features of the approach discussed in the review session: identify important features of the problem, review the knowledge which they possess about these features, compare knowledge to situation presented in the problem, select an immunological concept which would explain the situation, and finally evaluate appropriateness of answer to the original question.

The three sources of data taken together seem to indicate that the focus on teaching thinking skills may be a more viable way for Latham to understand the teaching-learning process than for him to concentrate innate differences and motivation.

\section{Conclusions}

This synopsis of the consultation project at the University of Minnesota was intended to provide an example of a unique approach to instructional improvement. This approach seeks to understand how the instructor understands the teaching-learning process (particularly student differences), to challenge the adequacy of this view in light of the instructor's stated intentions, and then to develop, implement, and evaluate new instructional techniques based on the instructor's revised conceptualization of the teaching-learning process. Consultation results in instructional changes which are valued by the faculty member because he is actively involved in analyzing his own teaching and creating approaches which suit his unique teaching environment. 


\section{References}

Argyris, C. and Schon, D.A. Theory in practice: Increasing professional effectiveness. New York: Dodd, Mead, 1973.

Gaff, J. Toward faculty renewal. San Francisco, Jossey-Bass, 1975.

Hunt, D. Theorists are persons, too: On preaching what you practice. In C. Parker (Ed.), Encouraging development in college students. Minneapolis: University of Minnesota Press, 1978.

Hunt, D. and Sullivan, E. Between psychology and education. Hinsdale, Illinois: Dryden Press, 1974.

Jenkins, J.J. Why it is hard to move from the laboratory to the classroom: A four-pointed problem. Paper presented at the Annual Convention of the American Psychological Association, San Francisco, 1977.

Lawson, J. Review of the literature on Perry research. Unpublished manuscript, University of Minnesota, 1978.

Nelson, W. and Siegel, M. Effective approaches to faculty development. Washington, D.C.: Association of American Colleges, 1980.

Perry, W.G. Forms of intellectual and ethical development in thecollege years. New York: Holt, Rinehart and Winston, 1970. 